\title{
BARTOLOME DE LAS CASAS Y DOMINGO DE SANTO TOMAS EN LA OBRA DE FELIPE WAMAN PUMA
}

\author{
POR \\ ROLENA ADORNO \\ Syracuse University
}

Entre las obras de la historiografía peruana indígena de los siglos XvI y xvir, la crónica de Felipe Waman Puma de Ayala es la única que comenta no sólo el pasado antiguo andino, sino también la actualidad colonial del virreinato. El primer nueva corónica y buen gobierno ${ }^{1}$, terminada hacia 1615, llama la atención porque el fin que se propuso fue el de proteger al pueblo andino y defenderlo de los colonizadores extranjeros. Al elaborar su alegato, Waman Puma se aprovechó del pensamiento liberal de la época. A través de nuestras investigaciones descubrimos que este hombre andino estaba plenamente al corriente de la naciente cultura literaria americana, es decir, de los primeros libros publicados en Sudamérica en la imprenta de Antonio Ricardo en Lima entre 1585 y $1600^{2}$. Al autor también le eran conocidas las letras más ilustres de España en la época, como, por ejemplo, las obras devocionales de fray Luis de Granada ${ }^{3}$. Lejos de tratar de negar la importancia de la cultura propia andina del autor en la articulación de su obra, nuestro proyecto es estudiar un aspecto del diálogo intercultural que es su libro. Trataremos de dilucidar la relación entre la argumentación de Waman Puma en pro de los derechos legales de su pueblo y el pensamiento jurídico de los defensores españoles del indio de las décadas anteriores: Bartolomé de las Casas y Domingo de Santo Tomás.

$\mathrm{Al}$ pretender delinear las correspondencias entre el texto de Waman Puma y los de estos dos dominicos, nuestro intento es ver el proceso retórico expresivo que combina y sintetiza las preocupaciones indígenas

${ }^{1}$ Felipe Guaman Poma de Ayala, Nueva corónica y buen gobierno (Codex peruvien illustré), ed. Paul A. Rivet (Paris: Institut d'Ethnologie, 1936; rpt. 1968).

2 Véase mi estudio "Las otras fuentes de Guaman Poma: Sus lecturas castellanas» (Histórica, 2:2, 1978, pp. 137-158).

${ }^{3}$ Véase también mi «El arte de la persuasión: El padre Las Casas y fray Luis de Granada en la obra de Waman Puma» (Escritura, Teoría y crítica literarias, Caracas, año IV, núm. 8, julio-diciembre 1979, pp. 167-189). 
peruanas con la retórica extranjera española, lo cual es un fenómeno que caracteriza, según nuestro parecer, la primera literatura hispanoamericana. Waman Puma regresó a la pureza de su ascendencia como originario de la provincia de las Lucanas en los Andes centrales del Perú a fin de legitimar su posición como hombre calificado para hablar claro. Al mismo tiempo entró en diálogo con los principios y preceptos europeos para así moldear y transformar lo ajeno de acuerdo con sus propias necesidades ideológicas. Al tener presente que el proceso retórico exigía la traducción de conceptos culturales andinos a razonamientos y propuestas comprensibles al monarca español como destinatario de la obra, se puede apreciar mejor lo que significa la composición que vamos a describir. Nutrido de sus lecturas a propósito, Waman Puma no eligió explicarle al rey Felipe el sistema andino de privilegios hereditarios ni el del dominio de las tierras. Al contrario, buscó y encontró en Domingo de Santo Tomás, y mayormente en Las Casas, el apoyo que más le servía para articular su protesta y sus demandas.

Un punto de contacto que merece señalarse es entre uno de los memoriales escritos por los dos dominicos al rey Felipe II en 1560 en defensa de los derechos de los caciques del Perú y el capítulo wamampumiano "Pregunta Su Magestad», en el cual el autor crea un diálogo entre el «autor y príncipe» y el rey Felipe III ${ }^{4}$. El diálogo consiste en las preguntas breves hechas por el monarca español al autor y las respuestas extensas de éste; el tema de la conversación es cómo defender a los indios de los abusos de los españoles. Los argumentos principales articulados aquí por Waman Puma corresponden a los adelantados por los dominicos en nombre de los caciques y señores naturales del Perú. Como Domingo de Santo Tomás y Las Casas, Waman Puma basa y disfraza su intento principal en los argumentos relacionados con los intereses financieros de la corona española. Los dominicos habían empezado su alegato destacando la necesidad moral y práctica de abolir la encomienda y las concesiones de los indios a perpetuidad. Con enérgicas advertencias previeron la declinación potencial de las fortunas de la monarquía española en las Indias si continuaba la disminución cada vez más grande en la población trabajadora andina causada por su explotación ${ }^{5}$. Waman Puma, en cambio, advirtió de la desaparición del pueblo indígena. Declaró que España no era nada sin las posesiones ultramarinas y sin sus habitantes

4 Bartolomé de las Casas y Domingo de Santo Tomás, «Memorial», en Opúsculos, cartas y memoriales, de Obras escogidas de Fr. Bartolomé de las Casas, ed. Juan Pérez de Tudela Bueso (tomo V, B. A. E., tomo CX, Madrid, 1958, pp. 465-468; cfr. Guaman Poma de Ayala, 1936, pp. 961-981).

${ }^{5}$ Las Casas, 1958, p. 466. 
naturales: «porque cin los yndios Vuestra Magestad no uale cosa, porque se acuerde Castilla es Castilla por los yndios» 6 .

Waman Puma tomó los argumentos centrales del memorial de Las Casas y Santo Tomás y los siguió no sólo en el diálogo ya referido, sino a lo largo de la obra; éstos se pueden resumir en tres puntos: Primero, la encomienda debía abolirse porque no había justificación legal para ella ${ }^{7}$. (Sobre la falta de justificación volveremos luego.) Segundo, a los encomenderos tanto como a otros no andinos se les debía prohibir entrar a los caseríos de los naturales ${ }^{8}$. Tercero, el rey debía restaurar y honrar los antiguos privilegios a los señores principales del reino del Perú ${ }^{9}$.

Además de la coincidencia entre estos argumentos generales por parte de los dominicos y Waman Puma se presenta un ejemplo muy concreto del aprovechamiento por el autor peruano de los escritos de los «grandes letrados», como dijera él, de la orden dominicana. Es curioso que Waman Puma jamás menciona el nombre de Las Casas; sin embargo, descubrimos que una de las consideraciones morales en el capítulo del mismo nombre en el Buen gobierno sigue punto por punto los argumentos propuestos por Las Casas en su Tratado de las doce dudas.

Se sabe que el Tratado circuló entre los dominicos en el virreinato peruano; a través de aquellos miembros activos de la orden en Huamanga (hoy Ayacucho), el cronista peruano debió de haberse enterado de la obra. El caso es que los principios de Las Casas pueden leerse línea por línea en la "Conzederación» que comienza: "Que aues de conzederar que todo el mundo es de Dios»:

Que aues de conzederar que todo el mundo es de Dios y ancí Castilla es de los españoles y las Yndias de los yndios y Guenea es de los negros. Que cada destos son lexítimos propetarios, no tan solamente por la ley como lo escriuió San Pablo, que desde dies años estaua de posición y se llamaua rromano ${ }^{10}$.

Este pasaje corresponde al Principio I del tratado mencionado de Las Casas. Allí dice que todos los infieles tienen jurisdicción sobre sus posesiones y territorios; a ello se añaden privilegios de soberanía. Este derecho a la jurisdicción es mandado no sólo por la legislación humana

6 Guaman Poma, 1936, p. 964.

${ }^{7}$ Cfr. Las Casas, 1958, p. 466, y Guaman Poma, 1936, pp. 549, 550, 559, 915, 958.

${ }^{8}$ Cfr. Las Casas, 1958, p. 467, y Guaman Poma, 1936, pp. 506, 524, 966, 977, 1117.

${ }^{9}$ Cfr. Las Casas, 1958, p. 467, y Guaman Poma, 1936, p. 958.

10 Guaman Poma, 1936, p. 915. 
según Las Casas (el «no tan solamente por la ley» de Waman Puma), sino también por la ley divina y natural ${ }^{11}$. La referencia que hace Waman Puma a San Pablo tiene su origen en el mismo Principio I: Las Casas cita a San Agustín, quien menciona la epístola de San Pablo a los romanos. Se refiere a Romanos, capítulo 13, primer verso, en donde el Apóstol insiste en la necesidad de la comunidad cristiana de obedecer al monarca, aunque gentil, bajo cuya jurisdicción vivía. Así, dice Waman Puma, San Pablo «se llamaua rromano», y de la misma manera, los españoles debían obedecer a las autoridades andinas al estar en el Perú.

En el pasaje a continuación del citado, Waman Puma reitera el Principio II del tratado lascasiano. El cronista advierte: «Que bien puede ser esta ley porque un español al otro español, aunque sea judío o moro, son españoles. Que no se entremete a otra nación cino que son españoles de Castilla, la ley de Castilla que no es de otra generación» ${ }^{12}$. Esto coincide con el segundo principio de Las Casas, en donde declara que los infieles que vivían entre cristianos eran vasallos de los reyes cristianos, como, por ejemplo, los judíos y moros que vivían en Castilla; así estaban obligados a obedecer las justas leyes de ese reino ${ }^{13}$. Los españoles en el Perú también debían de obedecer a las autoridades autóctonas.

Waman Puma cierra su argumento aprovechando otra vez el contenido del Principio II, que se puede resumir así: los indios del Nuevo Mundo, como infieles que nunca usurparon los territorios cristianos ni perjudicaron en alguna forma a las naciones cristianas, poseen sus propios reinos y ejercitan legítimamente su propia jurisdicción. Cualquier intervención de soberanía extranjera sería una violación de la ley natural divina ${ }^{14}$. A ese principio se referirá Waman Puma al reclamar los derechos de los naturales y colocar a los españoles en la categoría de los mitmaq (de mit'iy: enviar; enviado por su etnia de origen a cuidar intereses fuera) ${ }^{15}$ :

Los yndios son propetarios deste rreyno y los españoles naturales de España. Acá en este rreyno son estrangeros, mitimays. Cada uno en su ireyno son propetarios legítimos, poseedores no por el rrey cino por Dios y por justicia de Dios ${ }^{16}$.

"Bartolomé de las Casas, Tratado de las doce dudas, en Opúsculos, cartas y memoriales, de Obras escogidas de Fr. Bartolomé de las Casas (op. cit., pp. 478536; véase p. 486).

${ }^{12}$ Guaman Poma, 1936, p. 915.

${ }^{13}$ Las Casas, 1958, p. 488.

${ }^{14}$ Ibid., p. 489.

${ }^{15}$ Definición ofrecida por el Dr. Jorge L. Urioste, Universidad de Nevada, Las Vegas, Nevada.

${ }^{16}$ Guaman Poma, 1936, p. 915. 
Waman Puma concluye su argumento con lo siguiente: «Dios hizo el mundo y la tierra. Y plantó en ella cada cimiente: el español en Castilla, el yndio en las Yndias» ${ }^{17}$. En forma telegráfica, esto resume lo que dice Las Casas en su Principio II acerca del señorío de las cosas; se refiere otra vez al Principio I y cita el primer libro del Génesis, al cual alude igualmente Waman Puma ${ }^{18}$.

Quizá la clave y la prueba más gráfica de que es Las Casas a quien Waman Puma sigue como fuente es el dibujo que se encuentra en la página que está al lado de la exposición referida. Allí una figura se arrodilla humildemente ante un señor sentado en una silla. El título del cuadro es «Umildad, obedencia», y la figura piadosa se identifica como "Catón de Roma» ${ }^{19}$. Este representa al cardenal Cayetano, el teólogo italiano a quien citó Las Casas en su Principio II del Tratado de las doce dudas en cuanto al derecho de los infieles para gobernar sus propios territorios ${ }^{20}$. En efecto, Las Casas se apoyó en el razonamiento de Cayetano en cuanto a las varias clases de infieles para defender el derecho de las naciones de las Indias de tener y poseer sus reinos y tierras. Lo curioso es que Waman Puma convierte las citas eruditas en anécdotas sobre la vida personal de este autor tanto como lo hizo en el caso de San Pablo. Al crear narraciones acerca de la ejemplaridad de estos personajes, Waman Puma convierte la autoridad jurídica de San Pablo y del cardenal en ejemplos morales; el principio abstracto se reduce a la práctica. Así, el cronista pinta a San Pablo, que vivió en Roma por diez años bajo un rey gentil, y al cardenal Cayetano, quien obedecía a Dios, a su rey y a sus padres. A su turno, este Cayetano es el punto de comparación con los indios peruanos antiguos; dice Waman Puma: «El buen egenplo de Catón de Roma tenía los yndios deste rreyno» ${ }^{21}$.

Con esta declaración de Waman Puma llegamos al umbral de la transformación retórica e ideológica que mencionamos al principio. La analogía que hace Waman Puma entre el cardenal italiano del siglo xvi y los indios antiguos de la época prehispánica no es casual, sino cuidadosamente calculada. Es precisamente el aspecto anacrónico, la creencia y fe cristianas lo que resulta ser la clave de esta comparación. El hecho es que Waman Puma atribuye el conocimiento del Dios bíblico a los indios originales y la llegada del Evangelio al Nuevo Mundo a la época precolombina. Lejos de constituir una versión insensata de la historia, esta

\footnotetext{
${ }^{17}$ Ibid.

${ }^{18}$ Las Casas, 1958, p. 489.

19 Guaman Poma, 1936, p. 916.

${ }^{20}$ Las Casas, 1958, p. 490.

${ }^{21}$ Guaman Poma, 1936, p. 916.
} 
construcción simbólica se relaciona con, y se basa en, la argumentación lascasiana que acabamos de destacar.

Para describir esta estratagema volvemos a Domingo de Santo Tomás. Aunque Waman Puma no menciona explícitamente a Las Casas, sí habla de su colega peruano. En una parte de la Nueva corónica y buen gobierno, el cronista elogia al dominicano como hombre erudito, y en otra menciona sus logros literarios y lingüísticos ${ }^{22}$. Asimismo hace una objeción al trabajo de Domingo de Santo Tomás que nos es pertinente aquí: «El maystro fray Domingo de Santo Tomás ... no escriuió la desendencia de los primeros yndios, cómo, de qué manera fue y multiplicó antiguamente» ${ }^{23}$. En su Grammática o arte de la lengua general de los indios de los reynos del Perú, el primer quechuólogo exponía el hecho del origen de los indios como descendientes de Adán que habían emigrado a las Indias en la antigüedad ${ }^{24}$. En todo caso, Waman Puma habría considerado inadecuada tal versión por ser demasiado general. En su propia crónica identificó a los primeros indios como nietos del mismo Noé y, por consiguiente, les atribuía a ellos el conocimiento del Dios bíblico ${ }^{25}$.

Este punto de vista tenía claras implicaciones políticas en el tratado de Waman Puma sobre el «Buen Gobierno». Según el autor, la civilización andina se había desarrollado dentro de una antigua tradición de adoración del Dios bíblico, y los indios se habían cristianizado desde la supuesta visita de San Bartolomé a los Andes ${ }^{26}$. Como consecuencia, insistía nuestro autor en que los encomenderos no tenían por qué estar en el Perú; su misión pública de gobierno espiritual era superflua. Como tales, los encomenderos debían devolver inmediatamente todos los dominios temporales a los legítimos propietarios, a los naturales andinos ${ }^{27}$.

El uso imaginativo de mayor alcance que Waman Puma dio al repertorio ideológico de Las Casas fue la utilización del tema popular de que los andinos no habían sido conquistados en una guerra justa. Desechando otras versiones escritas del encuentro inicial entre españoles e indios con las que estaba familiarizado, Waman Puma reescribió ese importante episodio de la historia peruana en la manera siguiente: Martín Malqui de Ayala (no por coincidencia el padre de Waman Puma), como embajador

22 Ibid., pp. 912, 1079.

${ }^{23}$ Ibid., p. 1079.

${ }^{24}$ Domingo de Santo Tomás, Gramática o arte de la lengua general de los indios de los reynos del Perú (Lima: Universidad Nacional de San Marcos, 1951), p. 202.

${ }^{25}$ Guaman Poma, 1936, pp. 53, 54, 56.

${ }^{26}$ Ibid., pp. 92-93.

${ }^{27}$ Ibid., p. 549. 
de Huascar Inca, cedió voluntariamente la soberanía del Perú al embajador de Carlos V, Francisco Pizarro, en un ficticio encuentro en Tumbes en $1532^{23}$. Basando en este episodio su historia de la conquista española del Perú, Waman Puma declaró repetidamente que no hubo conquista militar del Tawantinsuyu porque los indios no se defendieron de los invasores ${ }^{29}$. Reiteró mordazmente este argumento en el capítulo sobre los encomenderos para negarles a los españoles cualquier derecho de jurisdicción sobre los naturales peruanos ${ }^{30}$.

Si bien el razonamiento de Las Casas y Domingo de Santo Tomás permanecía en un plano teórico, Waman Puma demandó la reparación de los agravios de los cuales era víctima. Esta tarea de convertir en práctica la teoría es el primer motor de su obra, desde la traducción de una voz de autoridad en ejemplo moral (San Pablo y Cayetano) hasta la misma reelaboración de la historia peruana en una "Nueva» corónica; la autoridad debe servir de ejemplo y la historia debe conformarse a las necesidades del pueblo al cual pertenece. Sobre la base de esta actitud, Waman Puma creó para sí mismo y a través de sus escritos un papel social que no estaba a su alcance en el mundo exterior. Para Waman Puma, su obra fue tanto una respuesta a un medio ambiente hostil como un intento de adoptar medidas correctivas contra él. Así, no es de sorprender que siguiera la línea de los escritores que empezó con Las Casas y Domingo de Santo Tomás al solicitar al rey por escrito sobre la necesidad urgente de devolver las tierras del Perú a sus propietarios legítimos. La presencia de las voces de los dominicos en las páginas de Waman Puma recalca la resonancia de un diálogo en defensa del hombre americano emprendido desde hace varios siglos.

\footnotetext{
${ }^{28}$ Ibid., pp. 375-376.

${ }^{29}$ Ibid., pp. 117, 162, 393, 447.

${ }^{30}$ Ibid., p. 550.
} 
